\title{
Waiting Time from Diagnosis to Treatment has no Impact on Survival in Patients with Esophageal Cancer
}

\author{
E. Visser, MD ${ }^{1}$, A. G. Leeftink, MSc ${ }^{2,3}$, P. S. N. van Rossum, $\mathrm{MD}^{1,4}$, S. Siesling, MD, $\mathrm{PhD}^{5,6}$, R. van Hillegersberg, \\ $\mathrm{MD}, \mathrm{PhD}^{1}$, and J. P. Ruurda, MD, PhD ${ }^{1}$ \\ ${ }^{1}$ Department of Surgery, University Medical Center Utrecht, GA, Utrecht, The Netherlands; ${ }^{2}$ Center for Healthcare \\ Operations Improvement and Research, University of Twente, Enschede, The Netherlands; ${ }^{3} \mathrm{UMC}$ Utrecht Cancer Center, \\ University Medical Center Utrecht, Utrecht, The Netherlands; ${ }^{4}$ Department of Radiotherapy, University Medical Center \\ Utrecht, Utrecht, The Netherlands; ${ }^{5}$ Department of Research, Netherlands Comprehensive Cancer Organization (IKNL), \\ Amsterdam, The Netherlands; ${ }^{6}$ Department of Health Technology and Services Research, University of Twente, Enschede, \\ The Netherlands
}

\begin{abstract}
Background. Waiting time from diagnosis to treatment has emerged as an important quality indicator in cancer care. This study was designed to determine the impact of waiting time on long-term outcome of patients with esophageal cancer who are treated with neoadjuvant therapy followed by surgery or primary surgery.

Methods. Patients who underwent esophagectomy for esophageal cancer at the University Medical Center Utrecht between 2003 and 2014 were included. Patients treated with neoadjuvant therapy followed by surgery and treated with primary surgery were separately analyzed. The influence of waiting time on survival was analyzed using Cox proportional hazard analyses. Kaplan-Meier curves for short ( $<8$ weeks) and long ( $\geq 8$ weeks) waiting times were constructed.
\end{abstract}

Results. A total of 351 patients were included; 214 received neoadjuvant treatment, and 137 underwent primary surgery. In the neoadjuvant group, the waiting time had no impact on disease-free survival (DFS) [hazard ratio (HR) 0.96, $95 \%$ confidence interval (CI) 0.88-1.04; $p=0.312]$ or overall survival (OS) (HR 0.96, $95 \% \mathrm{CI}$ $0.88-1.05 ; p=0.372)$. Accordingly, no differences were

(C) The Author(s) 2016. This article is published with open access at Springerlink.com

First Received: 28 December 2015;

Published Online: 24 March 2016

E. Visser, MD

e-mail: e.visser-3@umcutrecht.nl

J. P. Ruurda, MD, PhD

e-mail: j.p.ruurda@umcutrecht.nl found between neoadjuvantly treated patients with waiting times of $<8$ and $\geq 8$ weeks in terms of DFS $(p=0.506)$ and $\operatorname{OS}(p=0.693)$. In the primary surgery group, the waiting time had no impact on DFS (HR 1.03, $95 \% \mathrm{CI}$ $0.95-1.12 ; \mathrm{p}=0.443)$ or OS (HR $1.06,95 \%$ CI 0.99 $1.13 ; p=0.108)$. Waiting times of $<8$ weeks versus $\geq 8$ weeks did not result in differences regarding DFS $(p=0.884)$ or OS $(p=0.374)$.

Conclusions. In esophageal cancer patients treated with curative intent by either neoadjuvant therapy followed by surgery or primary surgery, waiting time from diagnosis to treatment has no impact on long-term outcome.

Esophageal cancer is the eighth most common cancer and the sixth most common cause of cancer-related mortality worldwide. ${ }^{1,2}$ Surgical resection is the cornerstone of curative treatment with a 5-year survival rate of 34-36\% in patients treated with primary surgery. ${ }^{2}$ Multimodality treatment with neoadjuvant chemoradiotherapy or perioperative chemotherapy is increasingly applied and results in improved 5-year survival rates of 36-47 \%. .6 $^{3-6}$

Waiting times have been shown to be an important quality indicator for cancer care. ${ }^{7}$ In the Netherlands, the period between diagnosis and treatment is currently recommended to be reduced to a maximum of 5 weeks, and all Dutch hospitals have been obliged to publish their waiting times once per month and submit these to the Dutch Healthcare authority. ${ }^{8,9}$ Waiting time before treatment is distressing for patients and impairs their quality of life. ${ }^{10-12}$ Several studies investigated the length of waiting time in esophageal cancer. ${ }^{13-18}$ However, these studies lacked survival analyses, are currently outdated, or only 
included patients treated with primary surgery. ${ }^{13-18}$ Therefore, literature about the impact of waiting time on the longterm outcome in patients with esophageal cancer is scarce.

This study was designed to determine the impact of waiting time from diagnosis to treatment on disease-free survival (DFS) and overall survival (OS) in patients with esophageal cancer undergoing esophagectomy with curative intent, either with or without neoadjuvant therapy.

\section{MATERIALS AND METHODS}

\section{Study Population}

Data regarding 426 consecutive patients who were planned for esophagectomy with curative intent for esophageal cancer at the University Medical Center Utrecht (UMC Utrecht), from October 2003 to December 2014, were extracted from a prospectively collected database. Exclusion criteria consisted of emergency esophagectomies, participation in the Barrett's esophagus surveillance program, detected unresectable tumor (cT4b) or metastatic disease (M1) intraoperatively, and in-hospital or 90-day postoperative mortality. Institutional review board approval was obtained, and the informed consent requirement was waived for this study.

\section{Pretreatment Workup}

A substantial proportion of the patients were referred to the UMC Utrecht for treatment after their esophageal cancer diagnosis was established in a referring hospital. The remaining patients had the UMC Utrecht as their firstline hospital and were directly referred by a general practitioner (GP). In all patients, upper gastrointestinal endoscopy with biopsy was performed to confirm the diagnosis of esophageal cancer. Further investigations included endoscopic ultrasound (EUS), computed tomography (CT) scanning of thorax and abdomen, and ultrasonography of the neck. F-fluorodeoxyglucose positron emission tomography (FDG-PET) was not regularly used but has become part of the standard staging in our center since July 2013. All patients were discussed at a multidisciplinary tumor board in which a definitive treatment plan was constructed.

\section{Treatment}

According to the Dutch guidelines, patients with locally advanced disease ( $\mathrm{cT} \geq 2$ or $\mathrm{cN}+$ ) received either perioperative chemotherapy or neoadjuvant chemoradiotherapy. ${ }^{3,4}$ Before June 2012, the standard treatment for patients with esophageal cancer in our center consisted of perioperative chemotherapy. ${ }^{3,6}$ From June 2012, patients received neoadjuvant chemoradiotherapy. ${ }^{4}$ Before 2008 , neoadjuvant therapy was not part of the standard protocol and most patients were operated on without neoadjuvant therapy. In addition, primary surgical esophageal resection was performed in patients who were not eligible for neoadjuvant treatment. After esophagectomy with en bloc lymphadenectomy, all patients underwent gastric tube reconstruction with a cervical anastomosis. All patients were divided into one of two groups, including a group of patients who received neoadjuvant treatment followed by surgery, and a group of patients who underwent primary surgery.

\section{Follow-Up}

Clinical and histopathological characteristics were retrieved from the database. The resected specimens were reviewed by pathologists in accordance with the 7th edition of the American Joint Committee on Cancer TNM staging system. ${ }^{19}$ A radical resection (R0) was defined using the College of American Pathologist criteria. ${ }^{20}$ Following hospital discharge, patients were followed at the outpatient clinic for 5 years. In case of clinical suspicion of tumor recurrence, diagnostic imaging was performed. For patients who were discharged after 5 years of follow-up, the general practitioner was contacted for additional information on recurrent disease. DFS was defined as the number of months from the start date of neoadjuvant therapy until the date of recurrent disease in the neoadjuvant group and from the date of surgery until the date of recurrent disease in the primary surgery group. OS was defined as the number of months from the start date of neoadjuvant therapy until the date of death or last follow-up in the neoadjuvant group and from the date of surgery until the date of death or last follow-up in the primary surgery group.

\section{Statistical Analysis}

The distribution of continuous characteristics was reported as median [interquartile range (IQR)] or mean \pm standard deviation (SD), and categorical variables were reported as numbers and percentages. For the neoadjuvantly treated group, waiting time was defined as the number of weeks from the date of diagnosis to the start date of neoadjuvant therapy. For the primary surgery group, waiting time was defined as the number of weeks from the date of diagnosis to the date of surgery. The date of the first upper gastrointestinal endoscopy, on which the diagnosis of esophageal cancer had been established by histology from biopsies, was used as date of diagnosis.

Spearman's rank correlation coefficients $(\rho)$ were calculated to determine whether waiting time from diagnosis to treatment was influenced by (i.e., correlated with) the 
baseline characteristics. Spearman's $\rho$ was interpreted as follows: a positive or negative correlation coefficient of $0.80-1.00$ was considered very strong; $0.60-0.79$, strong; $0.40-0.59$, moderate; $0.20-0.39$, weak; and $0-0.20$, very weak.

The prognostic influence of the studied parameters, including waiting time and all baseline characteristics of DFS and OS, was assessed using univariable Cox proportional hazard analysis, which provided hazard ratios (HRs) along with $95 \%$ confidence intervals (CIs). Studied parameters that yielded a $p$ value $<0.10$ in univariable analysis were entered in multivariable Cox proportional hazards models, separately for DFS and OS. The original scale of waiting time was used for Cox regression analysis, because logarithmic transformation did not improve the proportional hazard assumption.

In accordance with literature and based on guidelines, waiting time was initially categorized into three groups: $<5$, $5-8$, and $\geq 8$ weeks. ${ }^{9,18}$ However, due to a limited number of patients, the number of groups was reduced to two groups with representative sample sizes, consisting of short and long time waiters ( $<8$ and $\geq 8$ weeks), respectively. Both groups were compared using the log-rank test after construction of Kaplan-Meier survival curves. All statistical analyses were performed using IBM SPSS Statistics Version 21 for Windows (IBM Corp., Armonk, NY). A $p$ value $<0.05$ was considered statistically significant.

\section{RESULTS}

\section{Baseline Characteristics}

Of the 426 patients who were planned for esophagectomy in the study period, 59 were excluded because of emergency esophagectomy $(n=3)$, participation in the Barrett's esophagus surveillance program $(n=7)$, detected unresectable tumor (cT4b) or metastatic disease (M1) intraoperatively $(n=21)$, and in-hospital or 90 -day postoperative mortality $(n=29)$. In 15 patients, waiting time could not be calculated, because the date of diagnosis or the starting date of neoadjuvant therapy was unknown. The remaining 351 patients were included in this study (Table 1).

The number of patients in the neoadjuvant group was 214. Mean age at diagnosis was 63 years \pm 8.4 (SD). The majority of patients was male $(n=171,80 \%)$, received neoadjuvant chemoradiotherapy $(n=111,52 \%)$, underwent transthoracic esophagectomy $(n=176,82 \%)$, and was pathologically staged as ypT3-4a $(n=111,51 \%)$, ypN0 $(n=108,51 \%)$, and R0 $(n=198,93 \%)$. The primary surgery group consisted of 137 patients. Mean age at diagnosis was 64 years \pm 9.9 (SD). The majority of patients was male $(n=93,68 \%)$, underwent transthoracic esophagectomy ( $n=84,61 \%)$, and was pathologically staged as pT3-4a $(n=96,70 \%), \mathrm{pN}+(n=91,66 \%)$, and R0 $(n=117,85 \%)$.

\section{Waiting Time and Baseline Characteristics}

The median time from diagnosis to neoadjuvant treatment was 6.4 weeks (IQR 5.3-7.7) for patients in the neoadjuvant group. Spearman's rank correlation coefficients showed weak to very weak correlations of waiting time with all baseline characteristics ranging from -0.22 to +0.16 (Table 2). In the primary surgery group, patients had a median time from diagnosis to surgery of 9.7 weeks (IQR 8.0-13.1). Spearman's rank correlation coefficients showed weak to very weak correlations of waiting time with baseline characteristics ranging from -0.22 to +0.25 (Table 2). The median waiting time of excluded patients detected with an unresectable tumor (cT4b) or metastatic disease (M1) intraoperatively $(n=21)$ was 6.1 weeks (IQR 4.7-11.0) in the neoadjuvant group $(n=7)$ and 8.8 weeks (IQR 4.2-12.4) in the primary surgery group $(n=14)$.

\section{Waiting Time and Survival}

For surviving patients in the neoadjuvant group, the median follow-up was 28 months (range 7-75). Of the 214 patients, $102(48 \%)$ developed recurrent disease during follow-up. Median DFS was 16 months (range 3-75), whereas median OS was 19 months (range 5-77). The OS rates at 1 and 3 years were 84 and $48 \%$, respectively. Univariable analyses of all studied variables in relation to DFS and OS are presented in Appendix Table 5. Waiting time did not influence significantly the DFS (HR 0.96, $95 \%$ CI $0.88-1.04 ; p=0.312$ ) or OS (HR $0.96,95 \%$ CI $0.88-1.05 ; p=0.372$; Table 3). For DFS, multivariable analysis identified ypT3-4a stage, ypN+ stage, and irradicality as independent and significant prognostic factors associated with worse DFS. For OS, ypN+ stage remained independently and significantly associated with worse OS in multivariable analysis. In addition, a stratified analysis for type of neoadjuvant therapy showed that waiting time did not influence OS significantly in patients treated with chemotherapy (HR 0.92, $95 \%$ CI $0.81-1.03 ; p=0.159$ ) or in patients treated with chemoradiotherapy (HR 1.05, $95 \%$ CI $0.90-1.23 ; p=0.509$ ).

For surviving patients in the primary surgery group, the median follow-up was 56 months (range 10-135). During follow-up, 67 of 137 patients (49\%) developed recurrent disease. Median DFS in the primary surgery group was 18 months (range 2-133), whereas median OS was 23 months (range $2-135$ ). The OS rates at 1,3 , and 5 years were 80,50 , and $45 \%$, respectively. Univariable analyses 
TABLE 1 Baseline characteristics of 351 patients treated with neoadjuvant therapy followed by esophagectomy or primary surgery for esophageal cancer

\begin{tabular}{|c|c|c|}
\hline & $\begin{array}{l}\text { Neoadjuvant therapy } \\
\text { total }(n=214) n(\%)^{*}\end{array}$ & $\begin{array}{l}\text { Primary surgery total } \\
(n=137) n(\%)^{*}\end{array}$ \\
\hline Age at diagnosis, year $[$ mean $\pm \mathrm{SD}]$ & $63(8.4)$ & $64(9.9)$ \\
\hline \multicolumn{3}{|l|}{ Gender } \\
\hline Male & $171(80)$ & $93(68)$ \\
\hline Female & $43(20)$ & $44(32)$ \\
\hline \multicolumn{3}{|l|}{ ASA score } \\
\hline 1 & 49 (23) & $35(26)$ \\
\hline 2 & $136(64)$ & $70(51)$ \\
\hline$\geq 3$ & $29(14)$ & $32(23)$ \\
\hline \multicolumn{3}{|l|}{ Tumor location } \\
\hline Upper esophagus & $3(1)$ & $0(0)$ \\
\hline Middle esophagus & $30(14)$ & $29(21)$ \\
\hline Distal esophagus & $105(49)$ & $62(45)$ \\
\hline Gastroesophageal junction & $76(36)$ & $46(34)$ \\
\hline \multicolumn{3}{|l|}{ Neoadjuvant therapy } \\
\hline None & $0(0)$ & $137(100)$ \\
\hline Chemotherapy & $103(48)$ & $0(0)$ \\
\hline Chemoradiotherapy & $111(52)$ & $0(0)$ \\
\hline \multicolumn{3}{|l|}{ Surgical approach } \\
\hline Transthoracic & $176(82)$ & $84(61)$ \\
\hline Transhiatal & $38(18)$ & $53(39)$ \\
\hline \multicolumn{3}{|l|}{ Histological type } \\
\hline Adenocarcinoma & $175(82)$ & $92(67)$ \\
\hline Squamous cell carcinoma & 39 (18) & $44(32)$ \\
\hline Other & $0(0)$ & $1(1)$ \\
\hline \multicolumn{3}{|l|}{ pT stage } \\
\hline T0 & 39 (18) & $2(2)$ \\
\hline $\mathrm{T} 1-2$ & $64(30)$ & $39(28)$ \\
\hline $\mathrm{T} 3-4 \mathrm{a}$ & $111(51)$ & $96(70)$ \\
\hline \multicolumn{3}{|l|}{ pN stage } \\
\hline No & $108(51)$ & $46(34)$ \\
\hline N1 & $54(25)$ & 39 (29) \\
\hline $\mathrm{N} 2-3$ & $52(24)$ & $52(38)$ \\
\hline \multicolumn{3}{|l|}{ Radicality } \\
\hline R0 & $198(93)$ & $117(85)$ \\
\hline $\mathrm{R} 1$ & $16(8)$ & $20(15)$ \\
\hline \multicolumn{3}{|l|}{ Referral } \\
\hline By general practitioner & $23(11)$ & $34(25)$ \\
\hline By another hospital & $191(89)$ & $103(75)$ \\
\hline \multicolumn{3}{|l|}{ Year of diagnosis } \\
\hline $2003-2005$ & $2(1)$ & $34(25)$ \\
\hline 2006-2008 & $22(10)$ & $50(36)$ \\
\hline 2009-2011 & $91(43)$ & $33(24)$ \\
\hline 2012-2014 & $99(46)$ & $20(15)$ \\
\hline
\end{tabular}

$S D$ standard deviation, ASA American Society of Anesthesiologists

* Percentages may not add up to 100 due to rounding 
TABLE 2 Spearman's rank correlation coefficients $(\rho)$ for waiting time for patients treated with neoadjuvant therapy followed by esophagectomy or primary surgery for esophageal cancer

\begin{tabular}{lcc}
\hline & Neoadjuvant therapy & Primary surgery \\
\hline Age at diagnosis & 0.11 & 0.25 \\
Gender & 0.02 & 0.03 \\
ASA score & 0.16 & 0.14 \\
Tumor location & 0.05 & -0.03 \\
Type of neoadjuvant therapy & -0.08 & $\mathrm{n} . \mathrm{a}$. \\
Surgical approach & 0.02 & 0.22 \\
Histological type & 0.01 & 0.01 \\
pT stage & 0.06 & -0.22 \\
pN stage & 0.07 & -0.11 \\
Radicality & 0.01 & 0.09 \\
Referral & 0.16 & 0.10 \\
Year of diagnosis & -0.22 & 0.17 \\
\hline
\end{tabular}

ASA American Society of Anesthesiologists, n.a. not applicable Positive or negative coefficients indicate positive or negative correlations with 1 or -1 being the strongest positive or negative relationship

of all studied variables in relation to DFS and OS are presented in Appendix Table 6. Waiting time from diagnosis to surgery did not influence significantly DFS (HR $1.03,95 \%$ CI $0.95-1.12 ; p=0.443$ ) or OS (HR 1.06, $95 \%$ CI $0.99-1.13 ; p=0.108$; Table 4). For DFS, multivariable analysis identified pT3-4a stage and $\mathrm{pN}+$ stage as independent and significant prognostic factors associated with worse DFS. For OS, pN+ stage and irradicality remained independently and significantly associated with worse OS in multivariable analysis.

\section{Impact of Short versus Long Waiting Time on Long- term Survival}

In the neoadjuvant group, no significant differences were found between patients with short ( $<8$ weeks, $n=165)$ and long ( $\geq 8$ weeks, $n=49$ ) waiting times regarding DFS $(p=0.506)$ and OS $(p=0.693$; Figs. 1a, b). In addition, in the primary surgery group, short $(n=37)$ and long $(n=100)$ waiting times did not result in significant differences in terms of DFS $(p=0.884)$ or OS $(p=0.374$; Figs. 1c, d).

\section{DISCUSSION}

This single-center cohort study investigated the influence of waiting time on long-term outcome in patients who underwent esophagectomy with curative intent for esophageal cancer, either treated with neoadjuvant therapy or treated with primary surgery. This study showed that waiting time did not significantly impact long-term outcome for both patient groups.

This is the first study to demonstrate that waiting time does not significantly affect long-term outcome regarding DFS and OS for patients treated with neoadjuvant therapy followed by surgery for esophageal cancer. In line with previous studies, waiting time did not impact DFS or OS in patients treated with primary surgery. ${ }^{17,18}$ The majority of the included patients were treated within a time frame of approximately 3 months. Therefore, the findings of this study reflect the fact that if patients are treated within a clinically relevant waiting period, early treatment does not improve survival.

Because multimodality treatment was introduced recently as the standard of care, the median follow-up duration of 28 months is relatively short in the neoadjuvant group. However, median time to recurrence is 9 months and the majority of patients develop recurrent disease within 2 years after surgery. ${ }^{21,22}$ Therefore, the follow-up duration of the neoadjuvant group in this study was considered sufficient to assess accurately the impact of waiting time on both DFS and OS.

To provide more insight into the influence of waiting time on long-term outcome, waiting time was initially categorized into three groups in this study according to Grotenhuis et al. ${ }^{18}$ Due to a limited number of patients, two rather than three groups, consisting of patients with short ( $<8$ weeks) and long ( $\geq 8$ weeks) waiting times, were composed. This cutoff was used to create two groups with representative sample sizes. The results showed no difference in survival regarding DFS and OS for patients with waiting times of $<8$ weeks from diagnosis to the start of neoadjuvant therapy. In addition, for patients treated with primary surgery, no differences were found between short and long waiting times on long-term outcome.

In this study, waiting time was not influenced by one or more baseline characteristics. All correlations were weak to very weak (Spearman's rank correlation coefficient $<0.4$ ). This finding suggests that a longer waiting time did not result in worse tumor characteristics with more advanced disease or in a smaller rate of radical tumor resections. Patients with shorter and longer waiting times had comparable pTN stages and R0 resections. For patients treated with neoadjuvant therapy, the waiting time did not differ between the type of neoadjuvant therapy (neoadjuvant chemoradiotherapy or perioperative chemotherapy).

In other types of cancer, several studies reported mixed findings about the potential association between waiting time and long-term survival. For breast cancer, studies mainly reported better outcomes with shorter waiting time, whereas in lung cancer, mixed findings of positive, negative, and no associations were reported. ${ }^{23-27}$ For pancreatic 
TABLE 3 Univariable and multivariable analysis of influence of waiting time on disease-free survival and overall survival in patients treated with neoadjuvant therapy followed by esophagectomy for esophageal cancer

\begin{tabular}{|c|c|c|c|c|c|c|}
\hline & \multicolumn{3}{|c|}{ Univariable analysis } & \multicolumn{3}{|c|}{ Multivariable analysis } \\
\hline & HR & $95 \% \mathrm{CI}$ & $p$ value & HR & $95 \% \mathrm{CI}$ & $p$ value \\
\hline \multicolumn{7}{|l|}{ Disease-free survival } \\
\hline $\begin{array}{l}\text { Additional week waiting time } \\
\text { ypT stage }\end{array}$ & 0.96 & $0.88-1.05$ & 0.362 & 0.96 & $0.88-1.04$ & 0.312 \\
\hline T0 & Reference & - & - & Reference & & \\
\hline $\mathrm{T} 1-2$ & 1.55 & $0.69-3.47$ & 0.288 & 1.22 & $0.54-2.79$ & 0.635 \\
\hline $\mathrm{T} 3-4 \mathrm{a}$ & 3.94 & $1.89-8.25$ & $<\mathbf{0 . 0 0 1}$ & 2.40 & $1.10-5.22$ & 0.028 \\
\hline \multicolumn{7}{|l|}{ ypN stage } \\
\hline No & Reference & - & - & Reference & - & - \\
\hline N1 & 1.83 & $1.11-3.03$ & 0.019 & 1.72 & $1.03-2.88$ & 0.039 \\
\hline $\mathrm{N} 2-3$ & 4.42 & $2.77-7.03$ & $<\mathbf{0 . 0 0 1}$ & 3.09 & $1.81-5.25$ & $<\mathbf{0 . 0 0 1}$ \\
\hline \multicolumn{7}{|l|}{ Radicality } \\
\hline R0 & Reference & - & - & Reference & - & - \\
\hline $\mathrm{R} 1$ & 4.41 & $2.46-7.91$ & $<\mathbf{0 . 0 0 1}$ & 1.93 & $1.00-3.70$ & 0.049 \\
\hline \multicolumn{7}{|l|}{ Overall survival } \\
\hline $\begin{array}{l}\text { Additional week waiting time } \\
\text { ypT stage }\end{array}$ & 1.00 & $0.91-1.08$ & 0.910 & 0.96 & $0.88-1.05$ & 0.372 \\
\hline T0 & Reference & - & - & Reference & - & - \\
\hline $\mathrm{T} 1-2$ & 0.95 & $0.45-2.02$ & 0.895 & 0.71 & $0.33-1.54$ & 0.385 \\
\hline T3-4a & 2.54 & $1.31-4.94$ & 0.006 & 1.46 & $0.71-3.00$ & 0.300 \\
\hline \multicolumn{7}{|l|}{ ypN stage } \\
\hline No & Reference & - & - & Reference & - & - \\
\hline N1 & 2.07 & $1.25-3.43$ & 0.005 & 2.04 & $1.21-3.43$ & 0.007 \\
\hline N2-3 & 4.15 & $2.57-6.69$ & $<\mathbf{0 . 0 0 1}$ & 3.04 & $1.74-5.33$ & $<\mathbf{0 . 0 0 1}$ \\
\hline \multicolumn{7}{|l|}{ Radicality } \\
\hline R0 & Reference & - & - & Reference & - & - \\
\hline $\mathrm{R} 1$ & 4.40 & $2.46-7.87$ & $<\mathbf{0 . 0 0 1}$ & 1.90 & $0.99-3.66$ & 0.055 \\
\hline
\end{tabular}

$H R$ hazard ratio, $C I$ confidence interval

Analysis was performed using Cox regression model. Bold values indicate statistically significant results (e.g., $p<0.05$ ). Only waiting time and variables with $p<0.1$ from univariable analysis are reported and were used for multivariable analysis

and colorectal cancer, most studies reported no associations between waiting time and survival. $28-31$

Numerous reports showed that increased waiting time results in major psychosocial stress in cancer patients. Patients prefer to be treated as soon as possible for the fear of tumor progression. ${ }^{32-34}$ Until hard conclusions can be drawn on the effect of waiting time on patients' prognosis, efforts should be made to keep waiting time to a minimum. In the current study, the median waiting time between diagnosis and neoadjuvant treatment was 6.4 weeks, whereas in patients treated with primary surgery it was 9.7 weeks. The waiting time reflects resource availability and efficiency, which indicates that there is still room for improvement. ${ }^{35}$ However, the main reason for the long waiting time should be sought, because we are a tertiary referral center. To reduce waiting time, a more efficient diagnostic workup for patients with suspected esophageal cancer was recently introduced in our hospital, including rapid diagnostic pathways and frequent multidisciplinary team meetings for the establishment of a definitive treatment plan for each individual patient. ${ }^{36}$ This diagnostic workup resulted in a reduced median waiting time of 6.1 weeks for the neoadjuvant group and 8.1 weeks for the primary surgery group during the period of 2012-2014 (data not shown). Further steps still need to be taken to reduce the waiting time from the determination of the treatment plan until the start of treatment. The waiting time of the primary surgery group in this study is likely caused by the complexity of esophageal surgery planning. Esophagectomies are highly complex procedures with a median surgery duration of $6 \mathrm{~h}$ for transthoracic resection and therefore put a lot of pressure on operating room schedules. ${ }^{37}$ 
TABLE 4 Univariable and multivariable analysis of influence of waiting time on disease-free survival and overall survival in patients treated with primary surgery for esophageal cancer

\begin{tabular}{|c|c|c|c|c|c|c|}
\hline & \multicolumn{3}{|c|}{ Univariable analysis } & \multicolumn{3}{|c|}{ Multivariable analysis } \\
\hline & HR & $95 \% \mathrm{CI}$ & $p$ value & HR & $95 \% \mathrm{CI}$ & $p$ value \\
\hline \multicolumn{7}{|l|}{ Disease-free survival } \\
\hline Additional week waiting time & 0.97 & 0.91 & 0.222 & 1.03 & 0.95 & 0.443 \\
\hline \multicolumn{7}{|l|}{ ASA score } \\
\hline 1 & Reference & - & - & Reference & - & - \\
\hline 2 & 0.63 & $0.37-1.09$ & 0.100 & 0.95 & $0.53-1.72$ & 0.876 \\
\hline$\geq 3$ & 0.54 & $0.27-1.07$ & 0.075 & 0.95 & $0.32-1.39$ & 0.284 \\
\hline \multicolumn{7}{|l|}{ Surgical approach } \\
\hline Transthoracic & Reference & - & - & Reference & - & - \\
\hline Transhiatal & 0.50 & $0.29-0.86$ & 0.012 & 0.66 & $0.36-1.22$ & 0.182 \\
\hline \multicolumn{7}{|l|}{ pT stage } \\
\hline T0-2 & Reference & - & - & Reference & - & - \\
\hline $\mathrm{T} 3-4 \mathrm{a}$ & 4.08 & $2.02-8.26$ & $<\mathbf{0 . 0 0 1}$ & 2.51 & $1.13-5.57$ & 0.024 \\
\hline \multicolumn{7}{|l|}{ pN stage } \\
\hline No & Reference & - & - & Reference & - & - \\
\hline N1 & 2.89 & $1.35-6.20$ & 0.006 & 2.25 & $1.00-5.05$ & 0.029 \\
\hline $\mathrm{N} 2-3$ & 5.20 & $2.58-10.50$ & $<\mathbf{0 . 0 0 1}$ & 2.92 & $1.33-6.45$ & 0.008 \\
\hline \multicolumn{7}{|l|}{ Radicality } \\
\hline R0 & Reference & - & - & Reference & - & - \\
\hline $\mathrm{R} 1$ & 2.95 & $1.67-5.21$ & $<\mathbf{0 . 0 0 1}$ & 1081 & $0.97-3.37$ & 0.063 \\
\hline Additional year date diagnosis & 0.88 & $0.81-0.97$ & 0.009 & 0.94 & $0.85-1.05$ & 0.266 \\
\hline \multicolumn{7}{|l|}{ Overall survival } \\
\hline Additional week waiting time & 0.99 & $0.95-1.05$ & 0.803 & 1.06 & $0.99-1.13$ & 0.108 \\
\hline \multicolumn{7}{|l|}{ Tumor location } \\
\hline Middle esophagus & Reference & - & - & Reference & - & - \\
\hline Distal esophagus & 0.68 & $0.37-1.24$ & 0.211 & 0.54 & $0.28-1.03$ & 0.060 \\
\hline Gastro-esophageal junction & 1.74 & $0.96-3.15$ & 0.067 & 1.12 & $0.60-2.09$ & 0.728 \\
\hline \multicolumn{7}{|l|}{ pT stage } \\
\hline T0-2 & Reference & - & - & Reference & - & - \\
\hline $\mathrm{T} 3-4 \mathrm{a}$ & 2.95 & $1.62-5.38$ & $<0.001$ & 1.86 & $0.92-3.78$ & 0.086 \\
\hline \multicolumn{7}{|l|}{ pN stage } \\
\hline No & Reference & - & - & Reference & - & - \\
\hline N1 & 2.89 & $1.52-5.49$ & 0.001 & 2.76 & $1.40-5.45$ & 0.004 \\
\hline $\mathrm{N} 2-3$ & 3.25 & $1.78-5.94$ & $<0.001$ & 2.37 & $1.16-4.84$ & 0.018 \\
\hline \multicolumn{7}{|l|}{ Radicality } \\
\hline R0 & Reference & - & - & Reference & - & - \\
\hline $\mathrm{R} 1$ & 2.65 & $1.56-4.51$ & $<0.001$ & 2.08 & $1.17-3.70$ & 0.013 \\
\hline Additional year date diagnosis & 0.92 & $0.84-1.01$ & 0.070 & 0.97 & $0.88-1.08$ & 0.584 \\
\hline
\end{tabular}

Analysis was performed using Cox regression model. Bold values indicate statistically significant results (e.g., $p<0.05)$. Only waiting time and variables with $p<0.1$ from univariable analysis are reported and were used for multivariable analysis

ASA American Society of Anesthesiologists, $H R$ hazard ratio, $C I$ confidence interval

In our center, patients do not undergo standard disease evaluation after initial diagnosis of esophageal cancer until esophagectomy, and therefore possible tumor progression could only be detected during surgery. The median waiting time of 21 excluded patients detected with an unresectable tumor (cT4b) or metastatic disease (M1) intraoperatively and was comparable with the included patients who underwent esophagectomy with curative intent. Therefore, no significant selection bias of these patients is expected.

Of note, this study contains information about in-hospital waiting time only. Because patient waiting time (i.e., 
a Neoadjuvant group: Disease-free survival
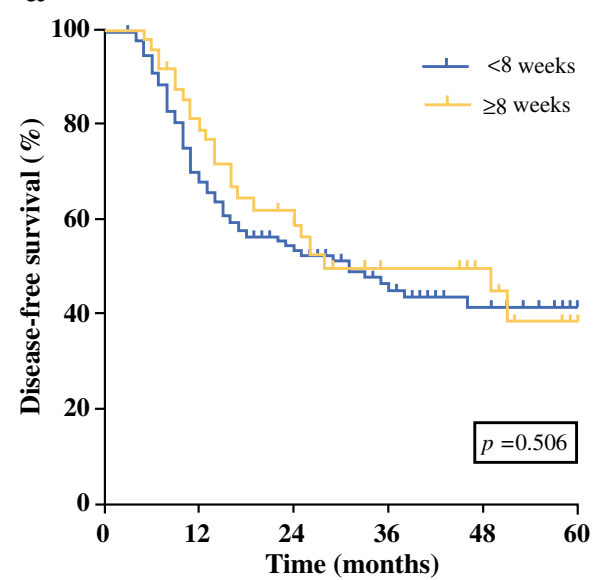

\begin{tabular}{|llllll|}
\hline Number at risk: & & & & & \\
$<8$ weeks 165 & 97 & 55 & 32 & 18 & 9 \\
$\geq 8$ weeks 49 & 34 & 20 & 13 & 10 & 1 \\
\hline
\end{tabular}

c Primary surgery group: Disease-free survival

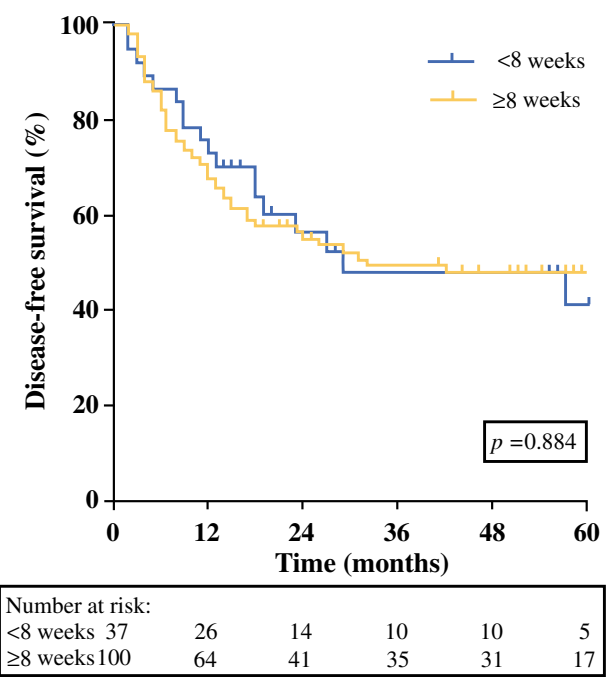

FIG. 1 The influence of short $(<8$ weeks) and long ( $\geq 8$ weeks) waiting time on disease-free survival $(\mathbf{a}, \mathbf{c})$ and overall survival $(\mathbf{b}, \mathbf{d})$ in patients treated with neoadjuvant therapy followed by surgery (a,

time between onset of symptoms and presentation to the GP) and doctor waiting time (i.e., time between presentation to the GP and endoscopy) account for a larger part of the total waiting time, these periods may still have an influence on long-term outcome. ${ }^{13,15,18}$ It would be interesting to identify what time frame is appropriate and whether a delay of any length does negatively influence long-term oncologic outcomes. Unfortunately, this study was not designed for such analysis.

In conclusion, this is the first study to demonstrate that waiting time does not impact long-term outcome in patients treated with neoadjuvant therapy combined with surgical resection for curable esophageal cancer. Furthermore, a b Neoadjuvant group: Overall survival
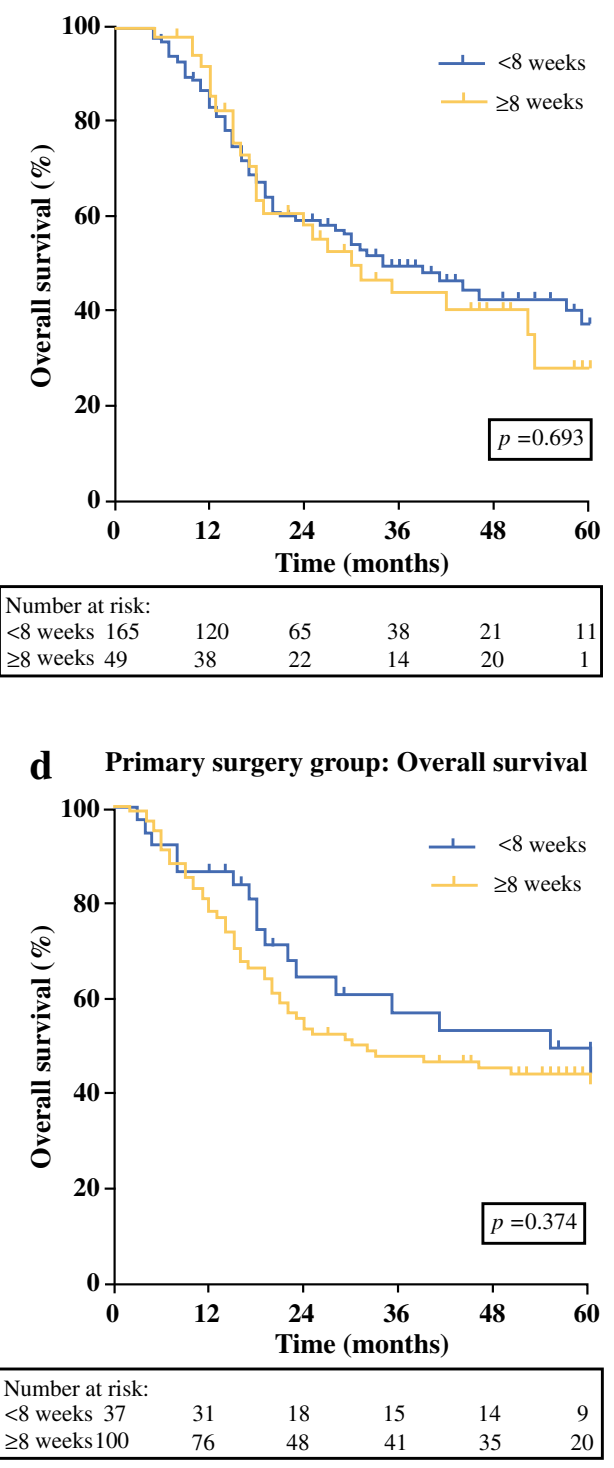

b), and patients treated with primary surgery (c, d) for esophageal cancer. Survival curves were plotted by the Kaplan-Meier method

longer waiting time did not affect the oncologic outcome for patients treated with primary surgery.

OPEN ACCESS This article is distributed under the terms of the Creative Commons Attribution 4.0 International License (http:// creativecommons.org/licenses/by/4.0/), which permits unrestricted use, distribution, and reproduction in any medium, provided you give appropriate credit to the original author(s) and the source, provide a link to the Creative Commons license, and indicate if changes were made.

\section{APPENDIX}

See Tables 5 and 6. 
TABLE 5 Univariable analysis of influence of waiting time on disease-free survival and overall survival in patients treated with neoadjuvant therapy followed by esophagectomy for esophageal cancer

\begin{tabular}{|c|c|c|c|c|c|c|}
\hline & \multicolumn{3}{|c|}{ Disease-free survival } & \multicolumn{3}{|c|}{ Overall survival } \\
\hline & $\mathrm{HR}$ & $95 \% \mathrm{CI}$ & $p$ value & HR & $95 \% \mathrm{CI}$ & $p$ value \\
\hline \multicolumn{7}{|l|}{ Univariable analysis } \\
\hline Additional week waiting time & 0.96 & $0.88-1.05$ & 0.362 & 1.00 & $0.91-1.08$ & 0.910 \\
\hline Age at diagnosis & 1.01 & $0.91-1.13$ & 0.805 & 1.01 & $0.98-1.03$ & 0.503 \\
\hline \multicolumn{7}{|l|}{ Gender } \\
\hline Female & Reference & - & - & Reference & - & - \\
\hline Male & 1.28 & $0.77-2.13$ & 0.342 & 1.01 & $0.62-1.65$ & 0.962 \\
\hline \multicolumn{7}{|l|}{ ASA classification } \\
\hline 1 & Reference & - & - & Reference & - & - \\
\hline 2 & 0.84 & $0.52-1.33$ & 0.452 & & & 0.389 \\
\hline$>3$ & 1.33 & $0.72-2.47$ & 0.366 & 0.81 & - & 0.480 \\
\hline \multicolumn{7}{|l|}{ Tumor location } \\
\hline Upper esophagus & Reference & - & - & Reference & - & - \\
\hline Middle esophagus & 0.59 & $0.12-3.06$ & 0.534 & 0.61 & $0.13-2.83$ & 0.524 \\
\hline Distal esophagus & 0.87 & $0.19-3.95$ & 0.853 & 0.74 & $0.18-3.05$ & 0.677 \\
\hline Gastroesophageal junction & 0.70 & $0.15-3.24$ & 0.647 & 0.53 & $0.13-2.23$ & 0.389 \\
\hline \multicolumn{7}{|l|}{ Neoadjuvant therapy } \\
\hline Chemotherapy & Reference & - & - & Reference & - & - \\
\hline Chemoradiotherapy & 0.90 & $0.60-1.34$ & 0.594 & 0.96 & $0.63-1.46$ & 0.849 \\
\hline \multicolumn{7}{|l|}{ Surgical approach } \\
\hline Transthoracic & Reference & - & - & Reference & - & - \\
\hline Transhiatal & 0.75 & $0.44-1.26$ & 0.272 & 0.72 & $0.43-1.22$ & 0.226 \\
\hline \multicolumn{7}{|l|}{ Histological type } \\
\hline Adenocarcinoma & Reference & - & - & Reference & - & - \\
\hline Squamous cell carcinoma & 0.87 & $0.49-1.53$ & 0.621 & 1.45 & $0.85-2.45$ & 0.172 \\
\hline \multicolumn{7}{|l|}{ pT stage } \\
\hline T0 & Reference & - & - & Reference & - & - \\
\hline $\mathrm{T} 1-2$ & 1.55 & $0.69-3.47$ & 0.288 & 0.95 & $0.45-2.02$ & 0.895 \\
\hline T3-4a & 3.94 & $1.89-8.25$ & $<0.001$ & 2.54 & $1.31-4.94$ & 0.006 \\
\hline \multicolumn{7}{|l|}{ pN stage } \\
\hline N0 & Reference & - & - & Reference & - & - \\
\hline N1 & 1.83 & $1.11-3.03$ & 0.019 & 2.07 & $1.25-3.43$ & 0.005 \\
\hline $\mathrm{N} 2-3$ & 4.42 & $2.77-7.03$ & $<0.001$ & 4.15 & $2.57-6.69$ & $<0.001$ \\
\hline \multicolumn{7}{|l|}{ Radicality } \\
\hline $\mathrm{R} 0$ & Reference & - & - & Reference & - & - \\
\hline $\mathrm{R} 1$ & 4.41 & $2.46-7.91$ & $<0.001$ & 4.40 & $2.46-7.87$ & $<0.001$ \\
\hline \multicolumn{7}{|l|}{ Referral } \\
\hline By general practitioner & Reference & - & - & Reference & - & - \\
\hline By another hospital & 0.94 & $0.52-1.72$ & 0.847 & 0.93 & $0.53-1.78$ & 0.928 \\
\hline Additional year date diagnosis & 1.01 & $0.91-1.13$ & 0.805 & 1.07 & $0.95-1.21$ & 0.250 \\
\hline
\end{tabular}

Analysis was performed using Cox regression model

ASA American Society of Anesthesiologists, $H R$ hazard ratio, $C I$ confidence interval 
TABLE 6 Univariable analysis of influence of waiting time on disease-free survival and overall survival in patients treated with esophagectomy for esophageal cancer

\begin{tabular}{|c|c|c|c|c|c|c|}
\hline & \multicolumn{3}{|c|}{ Disease-free survival } & \multicolumn{3}{|c|}{ Overall survival } \\
\hline & $\mathrm{HR}$ & $95 \% \mathrm{CI}$ & $p$ value & HR & $95 \% \mathrm{CI}$ & $p$ value \\
\hline \multicolumn{7}{|l|}{ Univariable analysis } \\
\hline Additional week waiting time & 0.97 & $0.91-1.02$ & 0.222 & 0.99 & $0.95-1.05$ & 0.803 \\
\hline Age at diagnosis & 0.98 & $0.96-1.01$ & 0.129 & 1.00 & $0.98-1.02$ & 0.876 \\
\hline \multicolumn{7}{|l|}{ Gender } \\
\hline Female & Reference & - & - & Reference & - & - \\
\hline Male & 1.27 & $0.75-2.16$ & 0.379 & 1.02 & $0.63-1.66$ & 0.932 \\
\hline \multicolumn{7}{|l|}{ ASA classification } \\
\hline 1 & Reference & - & - & Reference & - & - \\
\hline 2 & 0.63 & $0.37-1.09$ & 0.100 & 0.93 & $0.54-1.59$ & 0.782 \\
\hline$>3$ & 0.54 & $0.27-1.07$ & 0.075 & 0.98 & $0.53-1.83$ & 0.984 \\
\hline \multicolumn{7}{|l|}{ Tumor location } \\
\hline Middle esophagus & Reference & - & - & Reference & - & - \\
\hline Distal esophagus & 0.25 & $0.36-1.30$ & 0.246 & 0.68 & $0.37-1.24$ & 0.211 \\
\hline Gastro-esophageal junction & 0.18 & $0.82-2.89$ & 0.177 & 1.74 & $0.96-3.15$ & 0.067 \\
\hline \multicolumn{7}{|l|}{ Surgical approach } \\
\hline Transthoracic & Reference & - & - & Reference & - & - \\
\hline Transhiatal & 0.50 & $0.29-0.86$ & 0.012 & 0.77 & $0.48-1.24$ & 0.285 \\
\hline \multicolumn{7}{|l|}{ Histological type } \\
\hline Adenocarcinoma & Reference & - & - & Reference & - & - \\
\hline Squamous cell carcinoma & 0.74 & $0.43-1.26$ & 0.264 & 0.93 & $0.57-1.49$ & 0.748 \\
\hline Other & 3.33 & $0.45-24.45$ & 0.238 & 3.37 & $0.46-24.77$ & 0.233 \\
\hline \multicolumn{7}{|l|}{ pT stage } \\
\hline $\mathrm{T} 0-2$ & Reference & - & - & Reference & - & - \\
\hline T3-4a & 4.08 & $2.02-8.26$ & $<0.001$ & 2.95 & $1.62-5.38$ & $<0.001$ \\
\hline \multicolumn{7}{|l|}{$\mathrm{pN}$ stage } \\
\hline No & Reference & - & - & Reference & - & - \\
\hline N1 & 2.89 & $1.35-6.20$ & 0.006 & 2.89 & $1.52-5.49$ & 0.001 \\
\hline $\mathrm{N} 2-3$ & 5.20 & $2.58-10.50$ & $<0.001$ & 3.25 & $1.78-5.94$ & $<0.001$ \\
\hline \multicolumn{7}{|l|}{ Radicality } \\
\hline R0 & Reference & - & - & Reference & - & - \\
\hline $\mathrm{R} 1$ & 2.95 & $1.67-5.21$ & $<0.001$ & 2.65 & $1.56-4.51$ & $<0.001$ \\
\hline \multicolumn{7}{|l|}{ Referral } \\
\hline By general practitioner & Reference & - & - & Reference & - & - \\
\hline By another hospital & 1.50 & $0.82-2.75$ & 0.190 & 1.00 & $0.60-1.67$ & 0.999 \\
\hline Additional year date diagnosis & 0.88 & $0.81-0.97$ & 0.009 & 0.92 & $0.84-1.01$ & 0.070 \\
\hline
\end{tabular}

Analysis was performed using Cox regression model

$A S A$ American Society of Anesthesiologists, $H R$ hazard ratio, $C I$ confidence interval

\section{REFERENCES}

1. Torre LA, Bray F, Siegel RL, Ferlay J, Lortet-Tieulent J, Jemal A. Global cancer statistics, 2012. CA Cancer J Clin. 2015;65:87-108.

2. Pennathur A, Gibson MK, Jobe BA, Luketich JD. Oesophageal carcinoma. Lancet. 2013;381:400-12.

3. Cunningham D, Allum WH, Stenning SP, et al. Perioperative chemotherapy versus surgery alone for resectable gastroesophageal cancer. $N$ Engl J Med. 2006;355:11-20.
4. van Hagen P, Hulshof MC, van Lanschot JJ, et al. Preoperative chemoradiotherapy for esophageal or junctional cancer. $N$ Engl $J$ Med. 2012;366:2074-84.

5. Shapiro J, van Lanschot JJ, Hulshof MC, et al. Neoadjuvant chemoradiotherapy plus surgery versus surgery alone for oesophageal or junctional cancer (CROSS): long-term results of a randomised controlled trial. Lancet Oncol. 2015;16:1090-8.

6. van der Sluis PC, Ubink I, van der Horst S, et al. Safety, efficacy, and long-term follow-up evaluation of perioperative epirubicin, 
Cisplatin, and capecitabine chemotherapy in esophageal resection for adenocarcinoma. Ann Surg Oncol. 2015;22:1555-63.

7. Jaarrapportage Dutch Surgical Clinical Audit, DICA rapportage 2014. http://www.clinicalaudit.nl/jaarrapportage/2014/. Accessed 8 Sept 2015.

8. Dutch Cancer Society. Advies inzake wachttijdnormen in de kankerzorg. Amsterdam: Signaleringscommissie Kanker, Werkgroep: 'Wachtlijstproblematiek, specifiek gericht op de patient met kanker'. 2006.

9. VWS, Ministerie van Volksgezondheid, Welzijn en Sport. Brief Nieuwe wachttijdenregistratie; 30 mei. 2008.

10. Cimprich B. Pretreatment symptom distress in women newly diagnosed with breast cancer. Cancer Nurs. 1999;22:185-94.

11. Mor V, Allen S, Malin M. The psychosocial impact of cancer on older versus younger patients and their families. Cancer. 1994;74:2118-27.

12. Visser MR, van Lanschot JJ, van der Velden J, Kloek JJ, Gouma DJ, Sprangers MA. Quality of life in newly diagnosed cancer patients waiting for surgery is seriously impaired. J Surg Oncol. 2006;93:571-7.

13. Wang J, Liu F, Gao H, et al. The symptom-to-treatment delay and stage at the time of treatment in cancer of esophagus. Jpn J Clin Oncol. 2008;38:87-91.

14. Rothwell JF, Feehan E, Reid I, Walsh TN, Hennessy TP. Delay in treatment for oesophageal cancer. Br J Surg. 1997;84:690-3.

15. Witzig R, Schonberger B, Fink U, et al. Delays in diagnosis and therapy of gastric cancer and esophageal adenocarcinoma. Endoscopy. 2006;38:1122-6.

16. Martin IG, Young S, Sue-Ling H, Johnston D. Delays in the diagnosis of oesophagogastric cancer: a consecutive case series. BMJ. 1997;314:467-70.

17. Kotz BS, Croft S, Ferry DR. Do delays between diagnosis and surgery in resectable oesophageal cancer affect survival? A study based on West Midlands cancer registration data. Br J Cancer. 2006;95:835-40.

18. Grotenhuis BA, van Hagen P, Wijnhoven BP, Spaander MC, Tilanus HW, van Lanschot JJ. Delay in diagnostic workup and treatment of esophageal cancer. J Gastrointest Surg. 2010;14: $476-83$

19. Edge SB, Compton CC. The American Joint Committee on Cancer: the 7th edition of the AJCC cancer staging manual and the future of TNM. Ann Surg Oncol. 2010;17:1471-74.

20. Verhage RJ, Zandvoort HJ, ten Kate FJ, van Hillegersberg R. How to define a positive circumferential resection margin in T3 adenocarcinoma of the esophagus. Am J Surg Pathol. 2011;35: 919-26.

21. Blom RL, Lagarde SM, van Oudenaarde K, et al. Survival after recurrent esophageal carcinoma has not improved over the past 18 years. Ann Surg Oncol. 2013;20:2693-8.

22. Parry K, Visser E, van Rossum PS, Mohammad NH, Ruurda JP, van Hillegersberg R. Prognosis and treatment after diagnosis of recurrent esophageal carcinoma following esophagectomy with curative intent. Ann Surg Oncol. 2015;22 Suppl 3:1292-300.

23. Richards MA, Westcombe AM, Love SB, Littlejohns P, Ramirez AJ. Influence of delay on survival in patients with breast cancer: a systematic review. Lancet. 1999;353:1119-26.

24. Smith EC, Ziogas A, Anton-Culver H. Delay in surgical treatment and survival after breast cancer diagnosis in young women by race/ethnicity. JAMA Surg. 2013;148:516-23.

25. Torring ML, Frydenberg M, Hansen RP, Olesen F, Vedsted P. Evidence of increasing mortality with longer diagnostic intervals for five common cancers: a cohort study in primary care. Eur $J$ Cancer. 2013;49:2187-98.

26. Gonzalez-Barcala FJ, Garcia-Prim JM, Alvarez-Dobano JM, et al. Effect of delays on survival in patients with lung cancer. Clin Transl Oncol. 2010;12:836-42.

27. Yun YH, Kim YA, Min YH, et al. The influence of hospital volume and surgical treatment delay on long-term survival after cancer surgery. Ann Oncol. 2012;23:2731-7.

28. McLean SR, Karsanji D, Wilson J, et al. The effect of wait times on oncological outcomes from periampullary adenocarcinomas. $J$ Surg Oncol. 2013;107:853-8.

29. Pruitt SL, Harzke AJ, Davidson NO, Schootman M. Do diagnostic and treatment delays for colorectal cancer increase risk of death? Cancer Causes Control. 2013;24:961-77.

30. Currie AC, Evans J, Smith NJ, Brown G, Abulafi AM, Swift RI. The impact of the two-week wait referral pathway on rectal cancer survival. Colorectal Dis. 2012;14:848-53.

31. Thompson MR, Asiimwe A, Flashman K, Tsavellas G. Is earlier referral and investigation of bowel cancer patients presenting with rectal bleeding associated with better survival? Colorectal Dis. 2011;13:1242-8.

32. Gray RE, Fitch MI, Phillips C, Labrecque M, Klotz L. Presurgery experiences of prostate cancer patients and their spouses. Cancer Pract. 1999;7:130-5.

33. Jones RV, Greenwood B. Breast cancer: causes of patients' distress identified by qualitative analysis. $\mathrm{Br} J$ Gen Pract. 1994;44:370-1.

34. Rapoport Y, Kreitler S, Chaitchik S, Algor R, Weissler K. Psychosocial problems in head-and-neck cancer patients and their change with time since diagnosis. Ann Oncol. 1993;4:69-73.

35. Sneldiagnostiek UMC Utrecht. http://www.umcutrecht.nl/nl/ Ziekenhuis/Afdelingen/Cancer-Center/Sneldiagnostiek. Accessed 8 Sept 2015.

36. Ahn S, Cho J, Park CK, Kim S, Kim K. A large cohort of consecutive patients confirmed frequent HER2-positivity in gastric carcinomas with advanced stages. Lab Invest. 2013;93:142A.

37. Hulscher JB, van Sandick JW, de Boer AG, et al. Extended transthoracic resection compared with limited transhiatal resection for adenocarcinoma of the esophagus. $N$ Engl J Med. 2002;347:1662-9. 